\title{
Emotional Abuse and Neglect in the Workplace: A Method for Arrested OD
}

\author{
Joost Kampen \\ Vrije Universiteit
}

\author{
André Henken \\ Henken Advies
}

Emotional abuse and neglect in the workplace deserve wider recognition, because the process involved is insidious and paralyzes organizational development. An intervention strategy is presented that can be used in case of organizational neglect. The strategy's distinctive characteristics are:

- Guided organizational development by line management based on the zone of proximal competence and development of individuals and teams;

- Identification and interpretation of harmful, hidden dynamics;

- Effectuation of change through interactions on the work floor with aid of a more knowledgeable other (to teach operational management to guide subordinates' development);

- Effectuation of change in the lived reality by coaxing stakeholders out of their comfort zone while an $O D$ consultant remains psychologically available throughout the process.

CEOS, senior managers and management consultants assigned to change programs should be familiar with this method for restoring normal organizational life after a period of emotional abuse and neglect. The OD method presented was developed using more than 150 cases in both the public and private sector.

Keywords: Emotional Abuse and Neglect in the Workplace, Method for OD, Learning Cycle of OD, Recovery Process, Preconditions for Normalizing Daily Organizational Life

\section{INTRODUCTION}

The aim of this research project is to contribute to the field of OD and change management: a method of OD that can be devolved to other change agents. The description and replication of an intervention method is also a step in theory building, in developing a midrange theory (Eisenhart \& Graebner, 2007). The question that triggered our research was: why did our OD interventions fail to bring about the desired effect in organizations with persistant problems? In our work as OD practitioners we were struck by the lack of response to our change strategy. People neither embraced nor resisted our ideas. Daily life in the workplace just continued as if nothing had happened. There were few clues in the OD literature that could explain the phenomena we encountererd in our consultancy practice. Even studies on the dark side of organizations and leadership did not explain the root causes of what we saw and experienced (Vaughn, 1996; Lipmann-Blumen, 2005; Hanlon, 2016). 
At the start of our project, search queries in international literature data bases on 'abused organizations' and 'neglected organizations' provided no hits. But when we left out the word 'organizations' a large body of developmental psychology and child development literature came up. There, we discovered that the interactions between neglected children and their caretakers bore striking similarities to the dynamics we observed in our OD practice between employees and their managers. The concept of organizational neglect explains non-responsiveness in organizations as a result of laissez faire by management: it is a pedagogical frame of emotional neglect of children by parents and used here as a metaphor for organizational life. It provided us with another perspective to understand the phenomena in arrested OD (Kampen, 2015). Morgan (1986) explores various images of organizations, employing metaphors from biology, physics, political science and other disciplines. Surprisingly, organizational studies has not drawn much on parenting and child development. There are a few papers that discuss similarities between leadership and parenting, but none that focus on emotional neglect (Popper \& Mayseless, 2003). The concept of organizational neglect emphasizes developmental psychology and child development in particular, that is the field that deals with the problems encountered in raising and teaching children and young adults. Concepts from this field will be applied to learning and developmental difficulties in organizations which we characterize as emotionally neglected.

Over the past 15 years, we have elaborated and refined this approach as a way of reflecting, learning, documenting and contributing to research on OD (Langley et al., 2013). This study is a next step in our work of concept development in organization study (Gioia et al., 2013).

\section{An Example That Generated International Media Exposure: The Lived Reality of the Amsterdam Fire Brigade}

The necessity of a different method of organizational development is recently illustrated by the case of the Amsterdam fire brigade (Siggelkow, 2007). Twenty years of efforts of organizational change were met with persistent resistance and undermining. The commander appointed two years ago was assigned by the district council to tackle the 'macho culture' and modernize the mode of operations from a 'march out' approach to a more preventive approach. He was met with tactics of delay and sabotage. Last summer he suffered death threats from members of the staff after sticking to his plan to reform the 24 hour shift into an 8 hour shift (BBC news, 2018, July 17 \& Maloy, 2018).

\section{The Concept of Emotional Abuse and Neglect in the Workplace}

The lens of organizational neglect helps to understand the lived reality of the Amsterdam fire brigade and organizations with arrested OD in general. Neglect in the workplace is the prolonged lack or absence of supervision and control of organizational development, which leads to patterns of harmful interaction between management and staff (Kampen, 2015). Neglect is a gradual process. The consequences become visible only over time. In an organization plagued by neglect, relationships between management and staff are characterized by distrust and game playing. Employees pretend to be committed to the organization's objectives. Management and staff's behavioral patterns are mutually reinforcing; management's behavior provokes a knee jerk response in staff. In severe cases of neglect, relationships are so completely dysfunctional that reciprocity vanishes and self-preservation becomes employees' top priority. This reflects the lived reality of the Amsterdam fire brigade and many other organizations in our practice and research.

At the BAM 2018 conference we paid attention to the theory of emotional abuse and neglect in the workplace from a systemic perspective: the toxic triangle of deficits consisting of destructive organizational development, destructive leadership and destructive followership (Kampen \& Henken, $2018 \mathrm{~b}$ ). We introduced a diagnostic method to detect signs of neglect. In this paper we focus on the intervention strategy to restore from arrested OD caused by neglect. We developed the theory of the toxic triangle of neglect in organizations through our work as scholar-practitioners, having our institutional 'home' first in consultancy and second in education and academia (Schuiling \& Vermaak, 2017). 


\section{METHOD DEVELOPMENT}

The research methods we applied are multiple case study (Eisenhardt \& Graebner, 2007), reflection on action and reflection in action (Argyris \& Schön, 1978) and analysis of the diaries of OD consultants in the projects (Boje, 2001).

The theory of emotional abuse and neglect was applied in more than 150 cases over the last 15 years in both the public and private sector where we diagnosed signs of neglect. We studied cases in the OD practice of our consultancy firm in this period.

Each case lasted from 1 to 5 years. In $40 \%$ of the cases we monitored during 5 years, so we could see progress or stagnation in organizational development in a longitudinal way.

The cases were selected on the following criteria:

- the type of organizational problems: it had to do with deviant or counterproductive work behavior (Spector \& Fox, 2005), failing leadership (Erikson et al., 2015), failing programs for change in culture, restructuring of organizations that made things worse (Boonstra, 2004);

- in these organizations OD previous intervention strategies had failed: such as instrumental strategies, power strategies or strategies based on ownership;

- a representative selection of organizations: public and private sector, size from 250 to 12000 in headcount, branches such as services, health care, social services, education, governmental departments, municipalities, public transport, police, military, power companies and financial institutions.

Central to building theory from case studies is replication logic (Eisenhardt, 1989). That is, each case serves as a distinct experiment that stands on its own as an analytic unit. The theory building process occurs via recursive cycling among the case data, emerging theory, and later, extant literature.

In each case we worked with at least two OD professionals to have the possibility for mutual intervision and reflection. Also other OD professionals such as HR business partners and managers participated in our supervision group. We kept a diary of our observations, feelings, events and phenomena during our research. The longitudinal journal made it possible to analyse our cases over a longer period of time and to perform cross case analysis. We worked out some events comprehensively as storytelling, on paper or in words, in all detail to grap the meaning of what had happened (Boje, 2001). We presented the knowledge acquired in the scholarly domain by means of papers and contributions to symposia. We developed a course for change agents entitled 'learning to intervene in emotionaly abused and neglected organizations'. In the past seven years 20 groups of about 20 OD professionals each participated in the course. The participants intensified our reflection over the cases and the method developed.

\section{A METHOD TO RESTORE FROM ARRESTED OD}

We discovered phases in the intervention process that we started to describe and to use in the next case (Langley et al., 2013).

By describing our choice of interventions, we discovered patterns of recurring interventions in phases of the process. Initially we discovered four phases: reveal daily organizational life, confront actors on their responsibility, give feedback on their behavior and set an example using the theory from the domain of child abuse and neglect.

By documenting the process of intervening and how it worked out, we were able to carry over our method of intervening to the members of the organization, particularly to the members of the management who are primaraly responsible for the development of the organization.

We discovered that destructive patterns in the interaction processes in the organizations turned step by step into constructive patterns. In the successful OD interventions, management was in the lead and started by restoring a normal daily organizational life. All interventions took place in the workplace and during working hours. Members of the organization learned by doing. Through experience they 
discovered what normal daily organizational life is like. Ultimately, the method of OD we developed consists of a learning cycle in six phases (see Figure 1).

\section{FIGURE 1 LEARNING CYCLE OF OD}

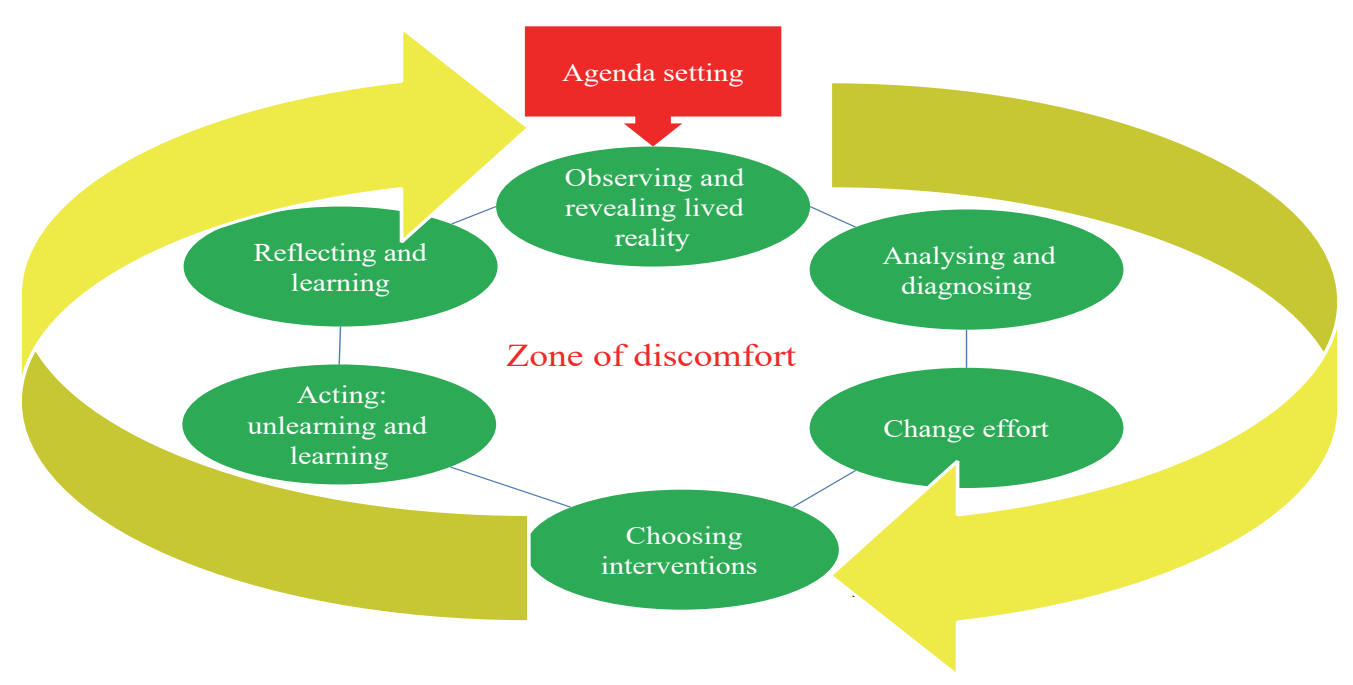

(Kampen, 2017).

\section{Observing and Revealing the Lived Reality}

This phase involves uncovering the behaviors, behavioral patterns and habits in the daily life of the organization. This is done by management in conjunction with staff and with the help of the OD consultant. Supervisors keep a diary to document their observations and what they think is remarkable. OD consultants focus in particular on patterns that people in the organization no longer notice, situations they ignore, or perks they have come to regard as entitlements. Supervisors are urged to look for behavior that transgresses boundaries. These boundaries may pertain to duties, roles or procedures, but also decency, the line between private life and work, or even personal boundaries, such as when employees intimidate or ignore their direct supervisors, deliberately go over their heads, or even harass them outside office hours as we saw in the case of the Amsterdam fire brigade (Erikson, 2018).

This phase could be detected in the cases as a process of data collection with the aim of looking at organizational reality. This process continues during the learning cycle.

\section{Analysing and Diagnosing}

This phase is about analyzing the patterns of behavior, the dynamics, the informal coalitions. Members of the organization are asked to complete a review consisting of questions like: what are the unwritten rules, when are you included or excluded as a newcomer, who sticks to obtained personal favors (in rostering for example), how does the informal hierarchy look like, what are habits and what goes without saying, do people share long histories, do they earn a favor from a colleague or their superior, do colleagues meet outside work etc. The diagnosis consists of recognizing the signs of neglect. This will be 'a look in the mirror' as leadership is often lacking. Members of operational as well as senior management have to step into the 'zone of discomfort' (Wierdsma, 2004).

This phase showed signs and patterns of resistance to face the truth by those responsible for daily affairs and operations. 


\section{Change Effort}

The change effort is aimed at restoring a normal organizational life. Setting the norm in 'normal' organizational life means specifying what is 'good' and what is 'bad'.

The change effort must simultaneously:

- $\quad$ put a stop to harmful interactions that keep unhealthy group dynamics in place;

- help people unlearn these interactions;

- encourage the learning of new interactions that make room for employees' needs, qualities and skills;

- reinforce these new interactions;

- place demands on, and set boundaries for, employees who are unlearning harmful interactions and learning new ones.

Implementing this change effort means going to the 'zone of discomfort' as a leader: it requires a different style, it requires presence, being there when people need you. In addition you will need support and trust from your superiors. This phase shows a 10 to $20 \%$ turnover in senior management because of their laissez faire leadership style.

\section{Choosing Interventions}

This phase is about intervening in daily reality. Supervisors set clear limits and monitor whether these are transgressed. Direct supervisors who tend to be lenient need help to grow a backbone. Their superiors must be highly adept at distinguishing between stakeholders' inability or unwillingness to change. A person whose inability is offset by a willingness to learn needs intensive coaching and a lot of practice. When someone's inability is caused by incompetence and unsuitability for the role, however, this person's future as a supervisor must eventually be reconsidered.

This phase showed an increase in turnover of 40 to $50 \%$ in positions of direct supervisors.

\section{Acting: Unlearning and Learning}

The fifth phase in the OD method is known as 'set an example' (and stop dwelling on the past). Establishing and following fixed routines brings organizational life to regularity and stability. It makes life, and management's behavior in particular, predictable again, giving the employees a sense of safety. Interventions are aimed at teaching the team to intervene on their own, in the here and now (Lewin, $1947 \mathrm{a}+\mathrm{b})$. This entails that people in the organization have to learn to reflect on how another person's behavior affects them and to say this directly to the person involved. Team meetings are held to this end, focusing on:

- increasing the participants' self-knowledge and awareness of their own behavior;

- increasing the participants' sensitivity to other people's behavior;

- developing a joint understanding of what constitutes normal and abnormal behavior in this particular context;

- increasing the participants' awareness and understanding of group dynamics;

- increasing the participants' diagnostic skills in interpersonal and intergroup interaction.

This phase showed a decrease in motivation and productivity (10 to 15\%) of staff members in the first year, a stabilization in the second year and an increase of satisfaction and productivity ( 25 to $30 \%$ ) in the third year.

\section{Reflecting and Learning}

Restoring normal organizational life is done during working hours. That's why peer intervision sessions are being held on a regular basis. The sessions are facilitated by OD consultants. To reflect on the effects of the interventions and the progress being made one- or two-day conferences are held. All the members of the management team participate and reflect on the organizational development and their own leadership. This also includes working as a team. Working on recovery in neglect situations requires both operational management and consultants to be resilient in the face of an avalanche of negative 
emotions. Such 'negative capability' (French, 2001) implies remaining patient when at a loss for words, allowing oneself to glean information from an emotion, and being able to absorb anxiety and formulate a palatable response. This means being able to keep a cool head in difficult and hostile conditions.

\section{APPLYING THE METHOD FOR OD}

The premise underlying experience-based or continuous learning is that a valuable experience nurtures the appetite: it is future oriented. Continuous learning is repeated exposure to an experience that contains a lesson we have already learned, so that we internalize it and turn it into a new skill. Every experience is a force that can be both positive and negative. Therefore, steering and directing experiences is essential in a neglected organization and must take place within a strict normative framework. After all, we do not want people to learn to tell more convincing lies, to become more ruthless in seeking power, or to shirk responsibility more effectively: the type of experience-based learning neglected employees are experts in! External training sessions are not a good alternative; their learning outcomes are poor in situations of neglect because people in the organization do not internalize what they learn. Rather, they learn to apply a trick for survival's sake. The four main interventions in daily organizational life - aimed not only at operational management and employees, but also at support staff, senior management and the board - are:

\section{Tackling Transgressive, Dysfunctional Behavior by People in the Organization}

This pertains to undesirable or impolite behavior at work which in many cases has gone unchecked for years, such as: frequent absenteeism, lateness, leaving early, taking time off during working hours, intentionally dawdling and taking longer to finish work, not answering phone calls or e-mails, gossiping about co-workers, criticizing direct supervisors behind their back, denying the existence of agreements, not completely finishing duties, and unauthorized trading of shifts with co-workers. Such 'bad' behavior can increase payroll costs by up to 30 percent (Pearson \& Porath, 2009). To get a grip on such workrelated dysfunctional behavior, direct supervisors must explicitly state their expectations regarding behavior and call out subordinates when they fail to meet them. Sometimes, however, this is not enough. Direct supervisors may have to draw a line, making clear there will be consequences if the transgression recurs.

\section{Restoring Work Routines}

Neglected organizations obviously have rules and procedures, agreements and instructions, just like healthy organizations. The difference is that none of them are enforced. Hence, employees start to ignore them or interpret them in self-serving ways. This is how unwritten rules start to replace written ones (Scott-Morgan, 1994). Of course, this happens in all organizations to an extent, but while in healthy organizations it may be intended to circumvent excessive bureaucracy, in cases of neglect unwritten rules are primarily aimed at self-preservation. Most organizations hold meetings at regular intervals. In neglected workplaces, attending meetings may have become optional; everyone is free to prioritize another activity. Another routine is vacation and leave. Unlike healthy organizations, where everyone is supposed to submit their requests before a particular date, neglected organizations have no strict deadlines and a solution can always be wangled for late requests. If not, employees simply call in sick. Job performance evaluations have become empty rituals or fallen by the wayside altogether because management is too busy dealing with other matters.

Restoring work routines is relatively simple because it involves no more than enforcing existing rules and procedures. Yet, this requires a lot of time and attention from everyone involved, particularly direct supervisors. They need to tackle something they have let slide for years. A majority will accept this and ultimately appreciate the enforcement and monitoring with thoughts like: 'Phew. Someone's finally taking charge'. A minority who used to benefit from operational management's laissez-faire approach will resist vehemently, as the return to routines often entails constraints on personal freedom or exposure of incompetence. 


\section{Normalizing Interactions at Work}

This normalization has nothing to do with correcting the misbehaviors mentioned above, but to the encouragement of positive interactions among co-workers and to humanizing relationships at work. For example: lending a hand when a co-worker has a big backlog, paying a co-worker a genuine compliment, or noticing that a usually talkative co-worker has been uncharacteristically quiet for a few days. Other examples are: speaking up when a co-worker is treated unfairly and when realizing someone has made a mistake. Often this pertains to behavior that is taken for granted or that people hesitate to bring up because it makes them uncomfortable. One type of interaction that is difficult to broach is the separation of work and private life. This pertains to friendships between co-workers, co-workers taking vacations together, and love relationships on the work floor between co-workers or a supervisor and a subordinate. Interventions are aimed at teaching the team to intervene on their own, in the here and now (Lewin, $1947 \mathrm{a}+\mathrm{b})$. This entails that people in the organization have to learn to reflect on how another person's behavior affects them and to say this directly to the person involved. Team meetings are held to this end, focusing on:

- increasing the participants' self-knowledge and awareness of their own behavior;

- increasing the participants' sensitivity to other people's behavior;

- developing a joint understanding of what constitutes normal and abnormal behavior in this particular context;

- increasing the participants' awareness and understanding of group dynamics;

- increasing the participants' diagnostic skills in interpersonal and intergroup interaction.

\section{Rebuilding Basic Structures and Functional Relationships in the Workplace}

This fourth intervention process is the most drastic because it affects the way everyone works. This intervention pertains to standardizing work processes, for example: standard client registration in health care, or recording student results in education. In neglected organizations, such work processes have never been standardized because management always feared staff's reaction to change and avoided making waves. Employees have therefore learned to record information in their own idiosyncratic, unverifiable manner out of concern for their clients or students. Another example of a basic structure in need of rebuilding, and one that was for instance very relevant to the situation at the Public Transport System of Amsterdam (GVB), is rosters. In a situation of neglect, management's laissez-faire conduct will have left room for dozens of exceptions based on private problems, rights granted in the past that have become entitlements, requests for leniency, and deals to favor friends or loved ones in the workplace. The original reasons for these exceptions are no longer pertinent; the exceptions have begun to lead a life of their own.

\section{FACING THE INEVITABLE BACKLASH}

Those who lead or supervise the recovery process are bound to face a backlash. They will have to deal with fake compliance and negativity. Just like the group leaders in a treatment center for neglected children (Trieschman, Whittaker \& Brendtro, 1969), direct supervisors bear the brunt of this resistance and they need all the support and protection they can get from their superiors. Unlike healthy organizations, neglected organizations require change agents to maintain a professional distance and refrain from entering into personal relationships with employees. At the same time, however, managers must show commitment: they cannot give up on employees and must persist in demanding they change their act. Direct supervisors must hold employees accountable for their own conduct. Management must maintain a functional, professional relationship with subordinates, as this is safest and most predictable. Personal relationships between management and staff in a neglected organization are a taboo. When operational management starts to take a stand and do what it is supposed to do, informal networks loose their influence. This will hold up a mirror to direct supervisors and consultants. The emotional impact of the recovery process and the mud-slinging that accompanies it will make direct supervisors more aware of 
their leadership skills. They will need to learn how to handle the strong resistance, hostility and personal attacks they will face, so it rolls off them like water off a duck's back. Consultants play a reflective and reinforcing role in this learning process. They can show direct supervisors that this negative response is part and parcel of the development process and is, in a sense, normal. After all, the workforce is coming to terms with the fact that change is inevitable and that they can no longer avoid their responsibilities.

Working on recovery in neglect situations requires both operational management and consultants to be resilient in the face of an avalanche of negative emotions. Such 'negative capability' (French, 2001) implies remaining patient when at a loss for words, allowing oneself to glean information from an emotion, and being able to absorb anxiety and formulate a palatable response. This means being able to keep a cool head in difficult and hostile conditions. Among soldiers in combat this is known as 'the ability to think under fire' (French, 2001, p. 481).

\section{THE RECOVERY PROCESS}

The recovery process takes about three full years to complete in a particular organizational unit. Such a unit is a performance unit clearly delineated by its location or products; it can also be a university department, a municipal service office, or a company branch. When more than one unit needs to be sorted out, the total duration will exceed three years because the involvement and vigilance required to make the process work preclude treatment of all units simultaneously and in the same tempo. Units need to be tackled in a staggered timeframe.

In studying the cases it appeared that the recovery process has three distinct phases and attending effects (Kampen \& Henken, 2018a):

1. The first, year-long phase places the greatest demands on senior management and the board. They keep discovering new problems and issues that have gotten out of hand as revelations of misbehavior keep emerging;

2. In the second phase, operations and support are starting to find the right balance. People are replaced because of incompetence, and even senior managers and support department staff are fired. Standardization of the work processes is starting to show results;

3. In the third phase, operational staff is learning to take a stand and assume responsibility for their duties. Social interaction is becoming more functional. Employees can give and take feedback and are starting to help each other out. Some ten per cent of the workforce continues to shirk responsibilities and sabotage the changes.

In an organization-wide recovery project, various organizational units will be in different stages of the OD process at any one time. This is due to possible delays in the recovery process of a particular unit resulting from changes in senior or operational management. In the cases studied, the full recovery process took 3 to 5 years.

This brings us to formulate a set of conditions that contributed to the success of the recovery process in abused or neglected organizations.

\section{PRECONDITIONS FOR NORMALIZING DAILY ORGANIZATIONAL LIFE}

To restore 'normal' organizational development we need to ensure that daily organizational life becomes predictable and that interactions between management and staff are functional. The working environment must be safe. Like the members of a family, the organization can only grow and develop in a safe environment. In both cases, the environment must meet certain requirements that establish routines and make daily life predictable. We have translated the requirements that apply to a safe child rearing climate into ten preconditions, subdivided into four categories, that an organization must meet in order to begin to reverse long-term neglect. 


\section{The Board's Attitude}

The three preconditions in this category are aimed at garnering or reinforcing the board's commitment to stop neglect and actively sponsor the recovery process. The board is the board of governors or the board of directors: the people who bear ultimate responsibility for the organization's management. The three preconditions in this category are analogous to the support and protection that parents/caretakers and social workers need in order to get daily life in a neglected family back on track. In an organizational setting, the board and senior management must provide this sponsorship so operational management can devote all its attention to normalizing working relationships in its departments and/or teams. There are three preconditions for change sponsorship:

\section{The Board Must Know How to Handle External Pressure on the Organization and Protect the Internal Organization.}

Neglected organizations that have made the headlines often face great external pressure to 'get their house in order'. In many cases subsequent negative media coverage had turned up the heat significantly. Sometimes, a board uses 'the market' or 'the government' to push for internal change. It should, of course, be wary of external demands and the risks they pose. But more importantly, the board should know what the organization can handle and how fast it can develop;

\section{The Board's Vision and Plans Must Be Geared to the Organization's Developmental Level and Not Overburden the Organization.}

The board must be prepared to face reality, to acknowledge the organization's current level of competence and to base its reform plans and promises to meet external demands on this reality. Ensuring that the proposed changes match organizational reality also entails adjusting the speed of their implementation and choosing appropriate interventions. The board should not be tempted to copy a concept that some board member remembers from a previous job. When assessing operational management and staff, it is crucial that the board can distinguish a lack of skills from an unwillingness to learn. If people are unwilling to change and grow, the board needs to take action and replace them;

The Board Must Be Commited to the Organization's Operating Core.

The board must be interested in the organization's operating core, the products or services the organization provides, and the people working there. It must be prepared to commit to the organization for a long time and allow this commitment to prevail over personal career opportunities elsewhere. In terms of engagement, the board members' leadership styles also come into play: 'idealists' or 'harmonizers' (Gilbert, 1996) are unlikely to want to lead a recovery process. It takes a particular type of personality to want to rock the boat and see the process through;

\section{Specification of Demands and Consequences of Non-Compliance}

The following two preconditions are intended to restore predictability to relationships in the workplace and to make the consequences of non-compliance clear. To normalize relationships, predictability and dependability must be built into daily life, while leaving enough room for play. It is mainly direct personal contact and social interaction that need to be given more structure; no one benefits from the creation of a paper tiger.

Normalizing daily life in the organization can only be achieved under the following two conditions:

\section{Expectations and Demands Concerning the Conduct of Management and Staff, Peers Amongst}

Themselves, and Staff and Customers, Must Be Made Explicit.

Demands are made explicit by initiating debate on what is considered normal and abnormal behavior. 'Normal' is an intersubjective notion. Expectations regarding conduct are not made explicit by writing them in a code of conduct and distributing them through flyers, posters and the intranet, but by holding an ongoing dialogue in the organization's daily life and management to reflect on what is considered 'normal' behavior; 
Non-compliance or Transgression of New Rules Established in the Common Framework of Reference Must Have Consequences.

Transgression of the new rules by displaying outward compliance, staying out of the line of fire or shirking responsibility, for instance, should have clear consequences. There should also be clear consequences when someone is proven unable to truly assume the professional role they were hired to play, especially when this inability is detrimental to co-workers or subordinates. The consequences must apply to all levels and positions in the organization. Once subordinates see that operational managers 'can't get away with it anymore' either, they will start to trust that real change is possible;

\section{Operational Management's Position}

The next three conditions pertain to operational management's positioning. Operational managers are the direct supervisors, such as team managers, who supervise employees working in operations. Just like parents/caretakers, operational managers must have the authority and the position that enable them to set limits and make themselves available. 'Position' means both the managers' formal position in the organizational structure, which is linked to formal responsibilities and competences, and their ability to fulfill the role. The third condition in this category (support) pertains to keeping a direct supervisor in position when a subordinate goes over their head and appeals to senior management or the board. The three conditions that are essential for strengthening operational management's position are:

\section{Operational Management Must Be Responsible for Performance.}

Direct supervisors must be responsible for their team or unit's performance, quality, HR and finance. This implies they must have formal authority and competences. Based on these, direct supervisors can specify their expectations with respect to their subordinates' performance. If this authority is shared, as in cases of dual management, matrix or network structures, there is always the risk that 'Mommy' and 'Daddy' will be played off against each other or will have different parenting styles. This makes it much harder to achieve consistent leadership in organizations. Success then depends on the personal chemistry between those who share authority;

\section{Direct Supervisors Must Be Able to Initiate and Maintain Routines that Make Organizational Life} Predictable.

To counteract neglect, direct supervisors must be prepared to assume their role. Usually, supervisors express a willingness to do so, but find it hard to maintain their resolve when they discover that familiar ways of interacting with their subordinates (like the 'you scratch my back and I'll scratch yours' culture at GVB) no longer work. Calling subordinates to task can be hard for direct supervisors who are used to avoiding conflict. They may be tempted to procrastinate and focus on other issues instead. Supervisors' ability to contribute to the recovery process is difficult to assess beforehand, but becomes obvious in practice. Tools like a 360-degree feedback questionnaire hinder rather than help in this situation;

\section{Direct Supervisors Must Receive Support from Their Superiors and the Board.}

Restoring daily organizational life to normalcy will unleash a backlash, which is very taxing for direct supervisors. They may start questioning themselves and fall prey to insecurity. What they need is support and affirmation from their superiors and recognition and appreciation from senior management and the board.

\section{Structuring and Directing the Recovery Process}

It is necessary to structure and direct the recovery process by setting clear tasks and roles and continually adjusting course based on the results of interventions. These requirements are the context for the last two conditions. The structuring and directing method is based on the programmed approach to treating neglectful parenting, in which every detail in daily life is addressed and everyone involved is assigned an unambiguous role and duties. In organizations too, the change process must be supervised very closely and carefully; everyone involved has to remain alert and on top of things. Managing 'from a 
distance' is out of the question in an organization recovering from neglect. The two conditions for successfully structuring the change process are:

\section{The Change Process Must Be Well-structured and the Structure Must Be Elaborated in Detail Before the Process Begins.}

Interventions are implemented in stages and according to a schedule. The duties and roles of all actors involved are contracted beforehand. Support departments make good on their name: they support and follow operations, rather than lead them. The people who play a role in the changes must be handpicked. These actors should be assessed to determine whether they can really make a difference in the process. It is important to be wary of observers and commentators ('HR ought to be included because of the collective bargaining agreement'). The whole process must be structured, managed and facilitated by the board;

The Interventions Must Continually Be Assessed for Effectiveness and Adjusted Accordingly.

It is more pertinent to ask 'Why did this intervention succeed, fail or only partly work?' than 'Why didn't this get done yet?' or 'How much will that save?' Assessing an intervention for effectiveness and tweaking it accordingly requires the time, attention and focus of everyone involved in the development process. It is definitely not a part-time job. Recovery from neglect demands total commitment from everyone: the board, senior management, support departments and operational management.

\section{DISCUSSION}

In this paper we have presented a method how to intervene in neglected organizations in order to restore 'normal organizational life' from arrested OD. The method evolved from our experience in and analyses of more than 150 cases in the last 15 years. We found that participative intervention strategies and instrumental interventions like leadership development programs and training did not work in neglected organizations because of absence of reciprocity due to arrested OD.

Planned change is aimed at improving an organization's performance and quality while cutting costs. It goes hand in hand with greater flexibility and improved responsiveness to clients' demands. Ongoing, rapid technological changes force organizations to adapt. Innovation is key to survival. Research has shown that the differences between public and private-sector organizations in this respect are smaller than once thought (Rainey \& Bozeman, 2000). However, this approach of planned change will not be succesful in neglected organizations. In such organizations something else has to be done first, i.e. to restore from neglect.

Neglect in the workplace must be dealt with before organizational development can take place. The (social) foundations must be solid if they are to support the development of the organization. Concepts from developmental psychology and child development serve as an analogy for shaping everyday, normal organizational life. Analogous concepts include:

- encouraging direct supervisors to take a stand, just like primary caretakers;

- initiating structure in the organization's social interactions, just like in children's daily lives, where good parents focus on 'orderliness, consistency and routine';

- applying functional relationships and roles in the organization, just like in the setting of institutional treatment of neglected children;

- setting limits, making people accountable for their behavior and letting them feel the consequences of transgressions, just like parents/caretakers need to do when dealing with neglected children.

Therefore line management has to take the lead, must step forward, show and demand the behavior that is considered normal among people in organizations. In most of the cases this means implementing again rules and behavior laid down in various organizational procedures but were 'forgotten' over time 
because no one took notice. Restoring normality is very strenuous and takes several years. The effort is only meaningfull when a number of conditions are fulfilled. The analogy with parenting is obvious.

The method of OD presented here proved to be an effective alternative to the classic change strategies that aim to realize a desired future state (Chin \& Benne, 1976). This method is situated in the lived reality and is performed by the line management from the start. In this method the gap between the 'soll' situation and the 'ist' situation is bridged. By structuring the interventions into 6 phases a process of learning by doing is enacted. The method helped leaders to guide the development of their subordinates, the teams and the organization as a whole. The method proved successful in different types of organizations.

There are some limitations to this study. Describing a method for intervening is helpful in structuring the phases and planning the interventions. It helps to transfer knowledge about the specific characteristics and conditions for intervening but is not a recepy or prescription for success. How can the risk of rigidity be overcome? How can the change agent attach to the zone of proximal development of different parts of the organization (Vygotsky, 1930)?

We paid attention to the board's attitude. How can the disturbance of turnover in the board be intercepted. How can continuation in the recovery process be assured when a new board is assigned.

In this study we did not pay attention to the durability of the recovery. How can the inevitable backlash be prevented. How to address the double bind of 'quick results' and recovery in the long run?

We studied more than 150 cases over a period of 15 years. The cases relate to organizations in the public and private sector. The sample consisted of larger organizations: approximately 250 to 12000 employees. Smaller organizations were underrepresented. A point to consider in future research is, are there significant differences from the organizations in this sample?

Further research is necessary of the role of the change agents. We discovered that not every OD consultant is fit and capable of fulfilling the role of the knowledgeable other. What specific competences are needed compared to OD in healthy organizations? Child development literature states that the supervisor needs to offer demandingness in helping the child and that the child needs to learn to take responsibility for his own behavior. This is a different perspective from the role of the process consultant that Schein (1998) describes. Humble inquiry will not help in recovery of neglect (Schein, 2013).

And last but not least: what is the influence of the curriculae of business schools on the attitude and leadershipstyle of their graduates and more specific on developing the responsiveness of managers to the needs of employees.

\section{CONCLUSION}

In our successful OD interventions in neglected organizations, management was in the lead and started by restoring a normal daily organizational life.

Our research resulted in the distinction of a learning cycle in six phases: 1. Observing and revealing the lived reality; 2. Analysing and diagnosing; 3. Change effort; 4. Choosing interventions; 5. Acting: unlearning and learning; and 6. Reflecting and learning. We could reproduce these phases in an approach to arrested OD.

The four main interventions in daily organizational life - aimed not only at operational management and employees, but also at support staff, senior management and the board - are: 1. Tackling transgressive, dysfunctional behavior; 2. Restoring work routines; 3. Normalizing interactions at work; and 4. Rebuilding basic structures and functional relationships in the workplace.

The recovery process takes about 3-5 full years to complete and has three distinct phases and attending effects. A set of conditions that contributed to the success of the recovery process in abused or neglected organizations relates to: 1. The Board's Attitude; 2. Specification of Demands and Consequences of Non-Compliance; 3. Operational Management's Position; amd 4. Structuring and Directing the Recovery Process.

All interventions took place in the workplace and during working hours. Members of the organization learned by doing. Through experience they discovered what normal daily organizational life is like. 
CEOs, senior managers and management consultants assigned to change programs should be familiar with this method for restoring normal organizational life after a period of emotional abuse and neglect in the workplace.

\section{REFERENCES}

Argyris, C., \& Schon, D. (1978) Organizational learning: A theory of action perspective. Reading, Mass: Addison Wesley.

BBC News. (2018, July 17). BBC Amsterdam fire chief Leen Schaap 'had death threats from staff. Retrieved from https://www.bbc.com/news/world-europe-44858538

Boje, D.M. (2001). Narrative Methods for Organizational \& Communication Research. London, Sage.

Boonstra, J.J. (2004). Dynamics of Organizational Change and Learning. Chichester: John Wiley \& Sons.

Chin, R., \& Benne, K.D. (1970). General Strategies for Effecting Changes in Human Systems, in W. G. Bennis, K. D. Benne, \& R. Chin (eds), The Planning of Change, (pp. 32-59), New York: Holt, Rinehart \& Winston.

Eisenhardt, K.M. (1989, October). Building Theories from Case Study Research. The Academy of Management Review, 14(4), 532-550.

Eisenhardt, K.M., \& Graebner, M.E. (2007). Theory Builing from Cases: Opportunities and Chalenges. Academy of Management Journal, 50(1), 25-32.

Erikson, A. (2018). Amsterdam's fire chief took on 'white male culture.' His employees tried to have him killed. The Washington Post, July 17. Retrieved from https:/www.washingtonpost.com/news/worldviews/wp/2018/07/17/amsterdams-fire-chief-tookon-white-male-culture-his-employees-tried-to-have-him-killed/?utm_term=.a86061 d7013b

Erikson, A., Shaw, B., Murray, J., \& Branch, S, (2015). Destructive leadership: causes, consequences and countermeasures. Organizational Dynamics, 44, 266-272.

French, R. (2001). "Negative capability”: Managing the Confusing Uncertainties of Change. Journal of Organizational Change Management, 14(5), 480-92.

Gilbert, M. (1996). The Process Communication Model: Understanding Ourselves and Others. NASSP Bulletin, 80, 75-80.

Gioia, D.A., Corley, K.G., \& Hamilton, A.L.(2013). Seeking Qualitative Rigor in Inductive Research: Notes on the Gioia Methodology. Organizational Research Methods, 16-1, 15-31.

Hanlon, G. (2016). The Dark Side of Management: a secret history of management theory. New York, Routledge.

Kampen, J. (2015). Emotional Abuse and Neglect in the Workplace: how to restore normal organizational life. London/New York, Palgrave.

Kampen, J. (2017). Leren interveniëren in verwaarloosde organisaties: lessen uit de geleefde werkelijkheid. Vakmedianet, Deventer. In English: Learning how to intervene in case of organizational neglect: lessons learned in the lived reality.

Kampen, J., \& Henken A.M. (2018a). Organizational neglect: the toxic triangle of deficits. Organizational Dynamics, 47, 241-249.

Kampen, J., \& Henken A.M. (2018b). Emotional abuse and neglect in the workplace. PDW at BAM 2018 conference: \#8629.

Langley, A., Smallman, C., Tsoukas, H., \& Ven van de, A.H. (2013). Process Studies of Change in Organization and Management: Unveiling Temporality, Activity and Flow. Academy of Management Journal, 56(1), 1-13.

Lewin, K. (1947a). Resolving Social Conflicts. New York: Harper.

Lewin, K. (1947b). 'Frontiers in Group Dynamics: Concept, Method and Reality in Social Science; Social Equilibria and Social Change. Human Relations, 1(1), 5-41.

https://doi.org/10.1177/001872674700100103 
Lipman-Blumen, J. (2005) The Allure of Toxic Leaders: Why We Follow Destructive Bosses and Corrupt Politicians - and How We Can Survive Them. New York: Oxford University Press.

Maloy, M. (2018). Amsterdam fire chief appointed to tackle 'macho culture' sent 'death threats from staff.' The Telegraph News, July 17. Retrieved from https://www.telegraph.co.uk/news/2018/07/17/amsterdam-fire-chief-appointed-tackle-machoculture-sent-death/

Morgan, G. (1986). Images of Organization. Beverly Hills: Sage Publications.

Pearson, C., \& Porath, C. (2009). The Cost of Bad Behavior: How Incivility is Damaging Your Business and What to Do About It. New York: Portfolio.

Popper, M., \& Mayseless, O. (2003). Back to basics: applying a parenting perspective to transformational leadership. The Leadership Quarterly, 14, 41-65.

Rainey, H.G., \& Bozeman, B. (2000). Comparing Private and Public Organizations: Empirical Research and the Power of the A Priori. Journal of Public Administration Research and Theory, 10(2), 447-69.

Schein, E.H. (1998). Process Consulting Revisited. Building the Helping Relationship. Boston, Addison Wesley Longman.

Schein, E.H. (2013). Humble Inquiry: The Gentle Art of Asking Instead of Telling. Boston, Addison Wesley Longman.

Schuiling, G.J., \& Vermaak, H. (2017). Four contexts of action research: Crossing boundaries for productive interplay. International Journal of Action Research, 13, 1, 5-23.

Scott-Morgan, P. (1994). The Unwritten Rules of the Game. New York: MacGraw-Hill.

Siggelkow, N. (2007). Persuasion with Case Studies. Academy of Management Journal, 50(1), 20-24.

Spector, P.E., \& Fox, S. (2005). Counterproductive Work Behavior: Investigations of actors and targets. Washington: American Psychological Associaltion, 151-174.

Trieschman, A.E., Whittaker, J.K., \& Brendtro, L.K. (1969). The Other 23 Hours: Child-Care Work with Emotionally Disturbed Children in a Therapeutic Milieu, New York: Aldine Pub. Co.

Vaughn, D. (1996). The Dark Side of Organizations: Mistake, Misconduct and Disaster. Annual Review of Sociology, 25, 271-305.

Vygotsky, L.S. (1978) [1930]. Mind in Society. Cambridge, MA: Harvard University Press.

Wiersdma, A.F.M. (2004). Beyond Implementation: Co-creation in Change and Development, in J.J. Boonstra (ed.) Dynamics of Organizational Change and Learning (Chichester: John Wiley \& Sons). 